\title{
Electron field emission from $\mathrm{SiO}_{x}$ films
}

\author{
A.A. Evtukh, I.Z. Indutnyy, I.P. Lisovskyy, Yu.M. Litvin, V.G. Litovchenko, P.M. Lytvyn, \\ D.O. Mazunov, Yu.V. Rassamakin, P.E. Shepeliavyi \\ Institute of Semiconductor Physics, NAS of Ukraine, 41 prospect Nauky, 03028 Kyiv, Ukraine \\ Phone: +38(044) 265 3852; e-mail: lisovsky@isp.kiev.ua
}

\begin{abstract}
Efficient electron field emission from silicon flat cathode coated with $\mathrm{SiO}_{x}$ film $(x \approx$ $0.3-0.5)$ was observed both before and after thermal $\left(1000{ }^{\circ} \mathrm{C}\right)$ annealing with subsequent etching in HF solution. Oxide films were produced by silicon thermal evaporation in vacuum $\left(10^{-5}\right.$ Torr). Using optical spectroscopy in visible and infrared ranges, as well as AFM technique, structural features of these films were investigated. It was shown that initial $\mathrm{SiO}_{x}$ film may be represented as $\mathrm{SiO}_{x}(\mathrm{Si})$ composite $(x \approx 1.2)$. Thermal annealing causes further phase segregation in film material, and it is transformed into $\mathrm{SiO}_{2}(\mathrm{Si})$ composite. During such a process, silicon grains size decreases and their density increases. The model of electron field emission from the surface of such films was proposed. It was supposed that limitation process of the current flow under high electric fields is connected with Fowler-Nordheim tunneling through barriers $\mathrm{Si}-\mathrm{SiO}_{x}-$ vacuum or $\mathrm{Si}-$ vacuum. Current peaks in emission $\mathrm{I}-\mathrm{V}$ characteristics were explained in the framework of resonance tunneling mechanism.
\end{abstract}

Investigated structures seems to be perspective for application as flat field cathodes in vacuum electronic devices and in flat panel field emission displays.

Keywords: electron field emission, flat cathodes, silicon oxide, nanostructures, structural transformations.

Paper received 24.12.02; accepted for publication 18.03.03.

\section{Introduction}

To improve the emission characteristics, silicon cathodes are performed in the form of tips, which are often covered with different films [1, 2]. In recent years, new types of coatings for silicon-based field emission cathodes have been intensively developed. At the same time, searching materials for flat emission cathode production is of essential interest. The reason is more perspective technological way to fabricate both field cathodes and cathode arrays. The principle moment for the flat emission cathode operation is the presence of emission centres, in particular, nanotips on its surface. It was shown recently [3] that high temperature treatment of $\mathrm{SiO}_{x}$ films $(x \approx 1.25)$ produced by vacuum thermal evaporation of silicon monoxide leads to substantial change of the film surface relief because of formation of silicon nanoinclusions. Such a nanorelief can, in principle, provide emission properties of the film, if the film has rather high conductivity (i.e. in the case of low oxygen content). Hence, in the present paper investigation was done to study electron field emission from the surface of $\mathrm{SiO}_{x}$ films with rather small oxygen content $(x \approx 0.3-0.5)$. Both initial and high temperature annealed films were under consideration.

\section{Experimental technique}

$\mathrm{SiO}_{x}$ layers were produced by thermal evaporation of silicon powder in vacuum $(2-3) \times 10^{-5}$ Torr, the deposition rate was chosen to obtain $x$ value about 0.3 . Substrates were both side polished Si wafers, what enabled us to measure infrared transmission spectra. Some layers were deposited onto glass wafers. During the deposition process, the temperature of substrate was $150^{\circ} \mathrm{C}$. Using quartz oscillator technique with accuracy $3 \%$, the film thickness $(d)$ and deposition rate were estimated. For the samples under investigation, the latter was $\sim 2$ to $3 \mathrm{~nm} / \mathrm{s}$. Measurements of the film thickness were taken by microinterferometer MII-4 and by a profilometer Dektak 3030. In the case of samples for optical measurements the $d$ value was $345 \mathrm{~nm}$. In the field emission experiments, oxides were substantially thinner $-d \approx 100 \mathrm{~nm}$. The samples were annealed in pure argon ambient under the temperature of $1000^{\circ} \mathrm{C}$ for 5-40 min. As it was shown earlier [4], such an annealing leads to formation of silicon nanoinclusions in oxide films.

Reflection (the angle of incidence $\sim 8^{\circ}$ ) and transmission spectra within the visible light range $(450-800 \mathrm{~nm})$ were measured using a spectrometer KSVU-23. 


\section{A.A. Evtukh et al.: Electron field emission from $\mathrm{SiO}_{x}$ films}

The IR transmission spectra were measured in the range of $800-1400 \mathrm{~cm}^{-1}$ using automated spectrometer IKS-25M. This range is well-known as containing the main absorption band of $\mathrm{SiO}_{x}$ with the maximum position $\left(v_{M}\right)$ varying within $\sim 1000-1100 \mathrm{~cm}^{-1}$ in dependence of chemical and structural oxygen states. The reference sample was a silicon substrate without oxide film deposited.

The surface profile of the oxide films was investigated using a DI NanoScope IIIa atomic force microscope. The measurements were carried out in tipping mode using CSG10 (NT-MDT) silicon probes with an Au reflective coating. The nominal curvature of a appex tip was $10 \mathrm{~nm}$.

The field emission current measurements were performed in the mode of the diode configuration in the vacuum system that was pumped out down to the stable pressure $10^{-6}$ Torr. The distance between the emitter and anode was constant and equal to $7.5 \mu \mathrm{m}$. The silicon substrate with $\mathrm{SiO}_{x}$ coating was used as a cathode (the diameter of emitting area was about $0.1 \mathrm{~cm}$ ). We used a molybdenum plate as anode. The applied voltage was changed within the range from 12 to $1600 \mathrm{~V}$. In order to avoid the breakdown, the resistor $0.56 \mathrm{M} \Omega$ was included into the used electric circuit. Prior to measurements, some samples were treated for 1 to $5 \mathrm{~min}$. in $1 \% \mathrm{HF}$ solution (that is known to etch silicon dioxide) or in mixture of $\mathrm{HF}: \mathrm{HNO}_{3}: \mathrm{H}_{2} \mathrm{O}$ with the component ratio 1:2:10 (capable to etch silicon).

\section{Experimental results and discussion}

In Fig. 1 the absorption spectrum of investigated $\mathrm{SiO}_{x}$ film is shown for visible light range in comparison with the results [5] obtained for silicon and $\mathrm{SiO}$ layers. It is known that for such layers the absorption edge location is determined by layer chemical content changing monotonically in dependence of oxygen content from the nearest infrared (for Si layer) up to ultraviolet (for $\mathrm{SiO}_{2}$ ). It is seen that absorption edge for investigated films is localized between spectra for $\mathrm{Si}$ and $\mathrm{SiO}$, i.e. for the cases $0<x<1$. The $x$ value can be estimated (as it was done in [6]), using theoretically calculated and experimentally measured [7] dependencies of photon energy $E_{04}$ (which corresponds to absorption coefficient $10^{4} \mathrm{~cm}^{-1}$ for $\mathrm{SiO}_{\mathrm{x}}$ layer) on $x$. For our samples it was obtained from the experimentally measured dependence of $E_{04}(x) x \approx 0.3$; comparison with calculated dependence of $E_{04}(x)$ gives $x \approx 0.5$.

In Fig. 2 IR transmission spectra for initial and annealed $\mathrm{SiO}_{x}$ films are presented. It is seen that after high temperature treatment the main absorption band of the oxide is shifted to high-frequency region (the minimum positions of the transmission band for initial and annealed films were 1032 and $1070 \mathrm{~cm}^{-1}$, respectively). The area and the shape of absorption band was also drastically changed due to annealing. The first fact is usually connected with phase change of the oxide film, which resulted from partial (or full) $\mathrm{SiO}_{x}$ decomposition onto silicon and silicon dioxide phases according to the scheme:

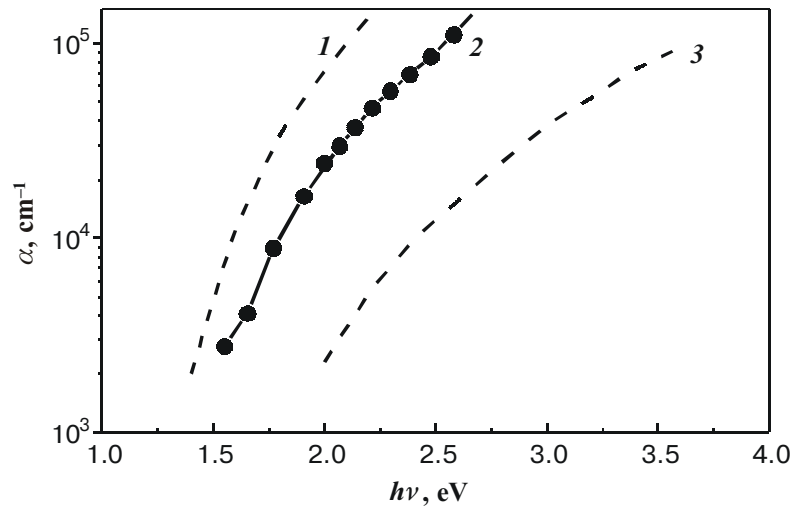

Fig. 1. The spectral dependence of the absorption coefficient of silicon (1), $\mathrm{SiO}$ layer (3) and investigated $\mathrm{SiO}_{x}$ films (2).

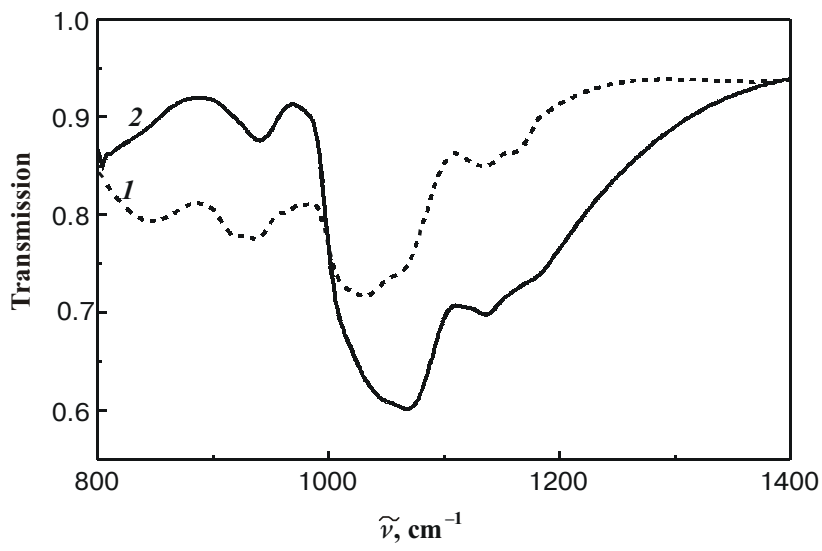

Fig. 2. Infrared transmission spectra for as-grown $(I)$ and annealed (2) $\mathrm{SiO}_{x}$ films.

$2 \mathrm{SiO}_{x} \rightarrow x \mathrm{SiO}_{2}+(2-x) \mathrm{Si}$.

This effect should lead to increase of effective meaning of stoichiometry index that was determined by IR measurements [8]. In the case of films produced by resistive sputtering of $\mathrm{SiO}$ powder, the value of $v_{M} \approx 1032 \mathrm{~cm}^{-1}$ is characteristic for oxides with $x \approx 1.2[6,8]$, and, for the first sight, is in a contradiction with the data obtained here from optical measurements in the visible light region. However, this contradiction can be explained taking into account that $\mathrm{SiO}_{x}$ films produced in the present work were not homogeneous, but consisted of silicon clusters and oxide phase, content of which was close to $\mathrm{SiO}$. It is known that optical properties of $\mathrm{SiO}_{x}$ layers can be rather well described by effective medium approximation on the base of optical characteristics of silicon and $\mathrm{SiO}_{2}$ for the whole range of $x$ values (from 0 to 2) [7]. Absorption of such material in the visible light region is determined by both $\mathrm{Si}-\mathrm{O}$ and $\mathrm{Si}-\mathrm{Si}$ chemical bonds that are distributed in $\mathrm{SiO}_{x}$. Hence, absorption of visible light determines average film stoichiometry taking into account both silicon-oxygen and silicon phases. Contrary, IR absorption band in the range of $1000<v_{M}<1100 \mathrm{~cm}^{-1}$ is connected with transverse stretching vibrations of bridg- 


\section{A.A. Evtukh et al.: Electron field emission from $\mathrm{SiO}_{x}$ films}

ing oxygen atoms in $\mathrm{Si}-\mathrm{O}-\mathrm{Si}$ "molecule", i.e. IR absorption "senses" only silicon-oxygen phase and "ignores" Si clusters.

The explanation proposed is also in agreement with the fact of substantial increase of the absorption band area due to sample annealing: this effect is connected with arising of the bridging oxygen concentration. The latter resulted from joining at elevated temperatures of silicon and oxygen dangling bonds that exist at large concentrations in initial sample. The meaning of $v_{M} \approx 1070 \mathrm{~cm}^{-1}$ and the shape of the spectral curve (in particular, existence of the high-frequency tail in absorption) are characteristic for almost stoichiometric $\mathrm{SiO}_{2}$ films $[9,10]$. This fact is an evidence that initial material in the result of annealing was decomposed into silicon and silicon dioxide phases almost entirely.

The nanorelief of $\mathrm{SiO}_{x}$ film surface and its transformation under subsequent treatments are shown in Figs 3 and 4 . It can be seen that the initial sample surface is characterized by high roughness connected mainly with large grains high up to $20 \mathrm{~nm}$. It is apparently caused by the $\mathrm{SiO}_{x}$ film deposition technology: the film was produced by means of deposition both silicon and $\mathrm{SiO}$ clusters. In this respect, atomic force microscopy results are correlated with above mentioned optical data that demonstrate the composite nature of the as-grown $\mathrm{SiO}_{x}$ layer structure. As a result of the heat treatment, the relief character substantially changes. The film surface becomes sufficiently uniform, and fine-grain film structure in this case is characterized by the roughness value in the range of 1 to $3 \mathrm{~nm}$. As mentioned above, the heat treatment of the sample causes decomposition of the initial material onto $\mathrm{SiO}_{2}$ and $\mathrm{Si}$ phases, the latter being in the form of nanoinclusions [4]. This fact appears, in particular, in the surface relief character of the annealed film. Subsequent sample treatment in HF solution did not affect geometrical relief of film surface (Fig. 4).

In Fig. 5 presented are the results of the electron field emission measurements (current-voltage characteristics) from surface of $\mathrm{SiO}_{x}$ films investigated in vacuum. It is seen that for initial sample the emission current $\left(10^{-7}\right.$ $\left.10^{-6} \mathrm{~A}\right)$ was observed at high voltages $(570-770 \mathrm{~V})$. The field emission from thermal treated samples was not observed in the whole range of the applied voltages. In contrast, for thermal treated samples subjected to subsequent etching in HF solution the emission increases in comparison with initial samples. In this case, the field emission appears already at the voltage $\sim 375 \mathrm{~V}$, and the maximum current amounts to the value of $\sim 10^{-5} \mathrm{~A}$. For annealed films that were etched in $\mathrm{HF}: \mathrm{HNO}_{3}: \mathrm{H}_{2} \mathrm{O}$ solution the emission was absent. We would note that for initial samples a sudden change of the emission current at the threshold voltage region was observed.

Some parameters of emission cathodes were determined from I-V characteristics. These are the field enhancement factor $\left(\beta^{*}\right)$ and effective emission area $(\alpha)$ (see Table 1). For comparison, in Table 1 the same parameters for silicon tip emitters are presented [2]. It can be seen that $\alpha$ for flat $\mathrm{SiO}_{x}$ cathodes exceeds one for silicon
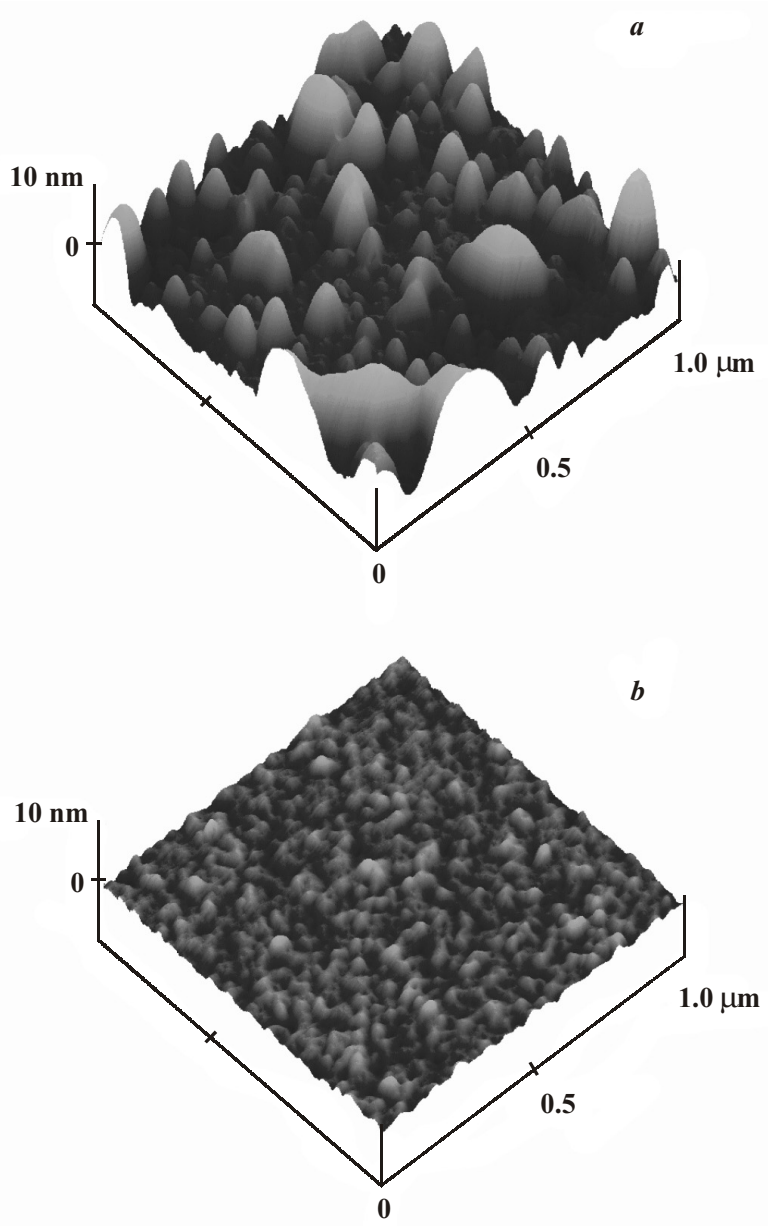

Fig. 3. Three-dimensional atomic-force microscopy images for as-grown $\mathrm{SiO}_{x}$ film $(a)$ and $\mathrm{SiO}_{x}$ film after annealing and etching in HF solution $(b)$.

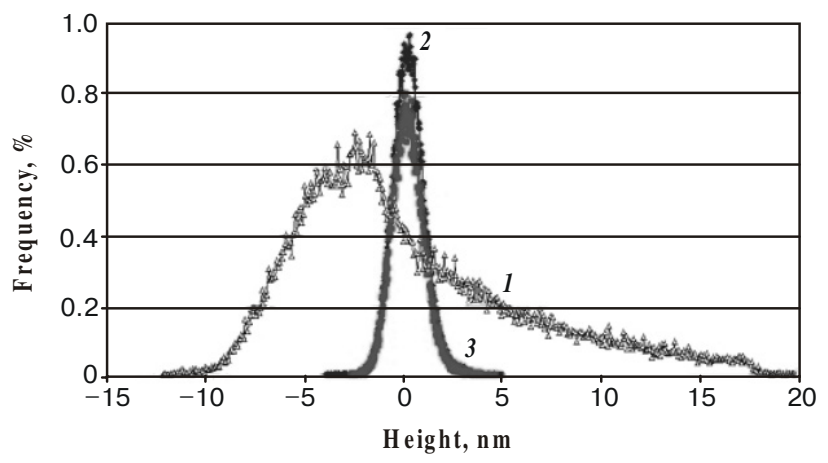

Fig. 4. The height distribution histogram of the $\mathrm{SiO}_{x}$ films: 1 - asgrown film; 2 - annealed film; 3 - film after annealing and subsequent etching in HF solution.

tip cathodes, and that thermal annealing $\mathrm{SiO}_{x}$ films leads to further increase in $\alpha$. The $\beta^{*}$ factor for flat cathodes, of course, is less than that for tip cathodes.

In field emission $\mathrm{I}-\mathrm{V}$ characteristics for annealed $\mathrm{SiO}_{x}$ films that were etched in HF solution, non-monotonous regions clearly appear within the range of voltages from 430 to $540 \mathrm{~V}$. They reveal themselves in the form of the 


\section{A.A. Evtukh et al.: Electron field emission from $\mathrm{SiO}_{x}$ films}

Table 1. Parameters of field emission cathodes.

\begin{tabular}{lll}
\hline \hline Type of the cathode & Field enhancement factor, $\beta^{*}, \mathrm{~cm}^{-1}$ & Efficiency field emission area, $\alpha, \mathrm{cm}^{2}$ \\
\hline Flat $\mathrm{Si}-\mathrm{SiO}_{x}$ (unannealed) & 62 & $1.4 \times 10^{-13}$ \\
\hline $\begin{array}{l}\text { Flat } \mathrm{Si}-\mathrm{SiO} \\
\text { and etching in HF solution) }\end{array}$ & 60 & $1 \times 10^{-12}$ \\
\hline Si tip cathode & 480 & $1.5 \times 10^{-14}$ \\
\hline \hline
\end{tabular}

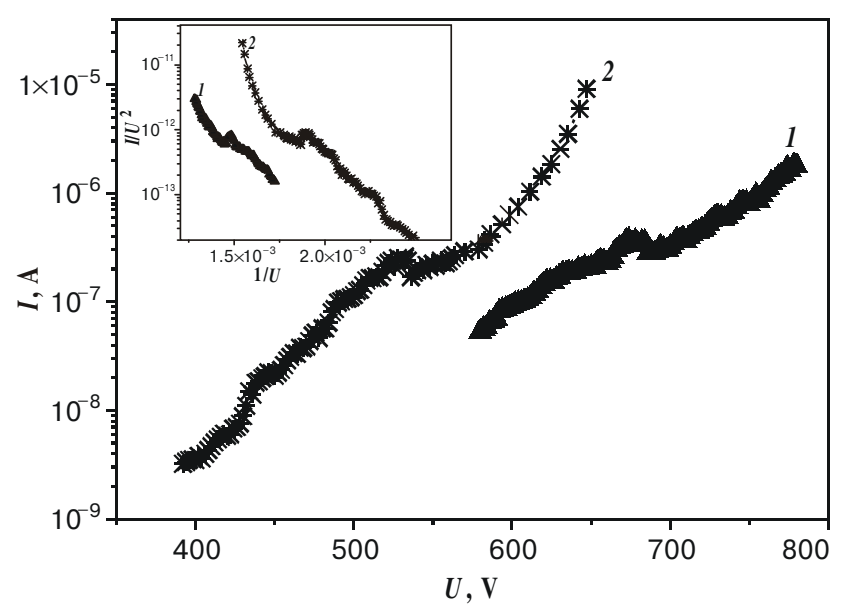

Fig. 5. I-V characteristics for electron field emission from $\mathrm{SiO}_{x}$ films: 1 - as-grown film; 2 - annealed and etched in HF solution film. The same in the Fowler-Nordheim coordinates (insert).

emission current peaks. For as-grown films, the field emission current peak is observed at the voltage $650 \mathrm{~V}$. We observed some-like non-monotonous I-V characteristics earlier, from $\mathrm{Si}$ tips covered by multi-layer $\mathrm{SiO}_{2}-\mathrm{Si}$ $\mathrm{SiO}_{2}$ film with the layer thickness $d=2 \mathrm{~nm}[11]$ as well as for silicon tips produced by laser surface modification [12]. The existence of regions with negative differential conductivity (peaks) on I-V characteristics is usually explained by quantum-size effects in such structures. It can be demonstrated as the appearance under certain electric fields of additional resonance tunneling electron mechanism. Non-monotonous regions in I-V field emission characteristics such as oscillations and peaks of the emission current also observed by other authors for different structures and materials [13-16].

The observed effect of the electron field emission from $\mathrm{SiO}_{x}$ film surface can be explained taking into account (i) phase composition of the initial and annealed oxide films, (ii) amplification of electric field on the surface silicon grains, and (iii) current-transport mechanisms during field emission.

As it was noted above on the base of the results of optical measurements, phase segregation onto $\mathrm{Si}$ and $\mathrm{SiO}_{\mathrm{x}}$ $(\mathrm{x} \approx 1.2)$ is already observed in initial oxide film. Obviously, at least a part of relief peaks on the film surface observed by means of AFM is connected with silicon inclusions. These Si grains simulate the electron field emission appearance due to local increasing of the electric field. Their presence in the oxide bulk, due to the same effect, also leads to relieved current flow through the film. If we assume that the silicon inclusions in initial oxide are covered by thin $\mathrm{SiO}_{x}$ layer, then under strong electric field electron carrying from $\mathrm{Si}$ substrate to oxide film outer surface occurs through silicon grains with tunneling through $\mathrm{SiO}_{x}$ layers. To leave the film, electrons overcome combined $\mathrm{Si}-\mathrm{SiO}_{\mathrm{x}}-$ vacuum barrier on external surface. This barrier is caused by the oxide layer covering the surface of silicon grains (Fig. 6a). Just the breakdown of this layer determines the initial sudden change of the field emission current. Further electron emission passes through $\mathrm{Si}-$ vacuum barrier.

The current peak observed in $\mathrm{I}-\mathrm{V}$ characteristics at voltage $650 \mathrm{~V}$ can be explained by appearance of the electron resonance tunneling mechanism. In conduction band of surface Si grains the local energy levels may arise due to the quantum-dimensional effect that provide realization of the resonant tunneling mechanism under certain electric field. After thermal annealing further Si and $\mathrm{SiO}_{2}$ phase segregation in $\mathrm{SiO}_{\mathrm{x}}$ films has been observed. Energy zone diagram for annealed structure (Fig. 6b) is similar to initial one. However, in this case, values of the energy barriers on $\mathrm{Si}_{-} \mathrm{SiO}_{2}$ interface are sufficiently higher than those at $\mathrm{Si}_{-} \mathrm{SiO}_{x}$ interface. As can be seen in Fig. 3, the sizes of Si inclusions for annealed film are less, and their density is larger. Considerable barrier height on Si$\mathrm{SiO}_{2}$ interface $(3.2 \mathrm{eV})$ is a reason for the absence of field emission at applied electric fields for annealed $\mathrm{SiO}_{x}$ films, since external $\mathrm{SiO}_{2}$-vacuum barrier has small probability of electron tunneling. During etching in HF solution, the external $\mathrm{SiO}_{2}$ layer was removed from $\mathrm{Si}$ inclusion surface. In this case, to be emitted, the electron should tunnel only through the vacuum barrier (Fig. 6c). Besides, due to thermal annealing the oxide film is densified, i.e. its thickness is decreased, as it was mentioned above. This circumstance also makes electron tunneling process more probable. The average sizes of the surface silicon inclusions in annealed $\mathrm{SiO}_{x}$ film have value of the order of 1-3 nm (Fig. 3), which is commensurable with the de Broglie wavelength for electrons in silicon. It is possible to expect that in this case the appearance of the peaks in $\mathrm{I}-\mathrm{V}$ emission characteristics is caused by resonance tunneling mechanism, too.

The mentioned above decrease of the threshold voltage for field emission at $\sim 80 \mathrm{~V}$ for annealed and subsequently etched $\mathrm{SiO}_{x}$ films comparing with the initial ones can be connected with appearance of two factors: (i) increase of the emission centres (silicon grains) concentra- 


\section{A.A. Evtukh et al.: Electron field emission from $\mathrm{SiO}_{x}$ films}
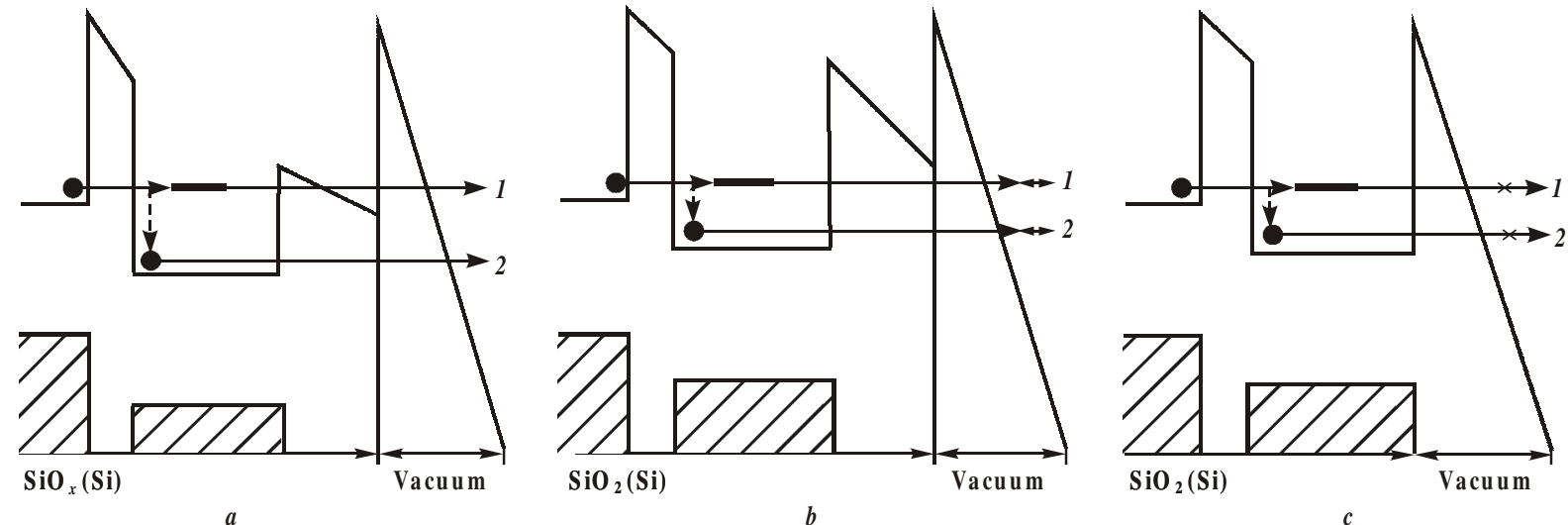

Fig. 6. Schematic energy diagram for field emission mechanism $\mathrm{Si}_{-} \mathrm{SiO}_{x}$ structures: initial $(a)$; after annealing $(b)$; after annealing and processing in HF solution $(c) .1$ - resonant tunneling process, 2 - Fowler-Nordheim tunneling process in vacuum.

tion, which leads to decreasing the distance between them; (ii) decrease of their sizes that causes increasing the local electric field in the field emission centre region.

The annealed films processing in the etchant for silicon removes the surface silicon inclusions, smoothes the film relief and, in such manner, makes the electron field emission from such films impossible.

\section{Conclusion}

Efficient electron field emission from the silicon flat cathode coated with $\mathrm{SiO}_{x}$ film $(x \approx 0.3-0.5)$ was observed both before and after thermal $\left(1000{ }^{\circ} \mathrm{C}\right)$ annealing with subsequent etching in $\mathrm{HF}$ solution. Oxide films were produced by silicon thermal evaporation in vacuum $\left(10^{-5}\right.$ Torr.). Using optical spectroscopy in visible and infrared ranges, as well as AFM technique, the structural features of these films were investigated. It was shown that initial $\mathrm{SiO}_{x}$ film can be represented as $\mathrm{SiO}_{x}(\mathrm{Si})$ composite $(x \approx 1.2)$. Thermal annealing causes further phase segregation in film material, and it is transformed into $\mathrm{SiO}_{2}(\mathrm{Si})$ composite. During such a process, silicon grains size decreases, and their density increases. The model of electron field emission from the surface of such films was proposed. It was supposed that the limitation process of the current flow under high electric fields is connected with FowlerNordheim tunneling through barriers $\mathrm{Si}-\mathrm{SiO}_{\mathrm{x}}$-vacuum or $\mathrm{Si}$-vacuum. Current peaks in emission $\mathrm{I}-\mathrm{V}$ characteristics were explained in the framework of resonance tunneling mechanism.

Investigated structures seems to be perspective for application as flat field cathodes in vacuum electronic devices and in flatpanel field emission displays.

\section{References}

1. C.A. Spindt, A thin film emission cathode // J. Appl. Phys., 39 (7), pp. 3504-3505 (1968).

2. A.A. Evtukh, V.G. Litovchenko, R.I. Marchenko, N.I. Klyui, V.A. Semenovich, C. Nelep, Parameters of the tip arrays covered by low work function layers // J. Vac. Sci. Technol. B., 14 (3), pp. 2130-2134 (1996).

3. I.P. Lisovskyy, I.Z. Indutnyy, B.N. Gnennyy, P.M. Lytvyn, D.O. Mazunov, A.S. Oberemok, N.V. Sopinskyy, P.E. Shepeliavyi, Phase-structural transformations in $\mathrm{SiO}_{\mathrm{x}}$ films throughout vacuum annealing // Fizika $i$ Tekhnika Poluprovodnikov, 37 (1), pp. 98-103 (2003) (in Russian).

4. V.Ya. Bratus', V.A. Yukhimchuk, L.I. Berezhinsky, M.Ya. Valakh, I.P. Vorona, I.Z. Indutnyy, T.T. Petrenko, P.E. Shepeliavyi, I.B. Yanchuk, Structural changes and formation of silicon nanocrystallites in $\mathrm{SiO}_{\mathrm{x}}$ films // Fizika i Tekhnika Poluprovodnikov, 35 (7), pp. 854-860 (2001) (in Russian).

5. H.R. Philipp, Optical and bonding model for non-crystalline $\mathrm{SiO}_{\mathrm{x}}$ and $\mathrm{SiO}_{\mathrm{x}} \mathrm{N}_{\mathrm{y}}$ materials // J. Non-Cryst. Solids, 8-10, pp. 627-632 (1972).

6. A.L. Shabalov, M.S. Feldman, Optical and dielectric properties of thin $\mathrm{SiO}_{\mathrm{x}}$ films of variable composition // Thin Solid Films, 110, pp. 215-224 (1983).

7. G. Zuther, Dielectric and optical properties of $\mathrm{SiO}_{\mathrm{x}} / /$ Phys. Stat. Sol. (a), 59, pp. K109-K113 (1980).

8. M. Nakamura, Y. Mochizuki, K. Usami, Y. Itoh, T. Nozaki, Infrared absorption spectra and compositions of evaporated silicon oxides // Solid State Communications, 50 (12), pp. 1079-1081 (1984).

9. W.A. Pliskin, H.S. Lehman, Structural evaluation of silicon oxide films // J. Electrochem. Soc., 112 (10), pp. 1013-1019 (1965).

10. I.W. Boyd, J.I.B. Wilson, A study of thin silicon dioxide films using infrared absorption techniques // J. Appl. Phys., 53 (6), pp. 4166-4172 (1982).

11. V.G. Litovchenko, A.A. Evtukh, Yu.M. Litvin, N.M. Goncharuk, V.E. Chaika, Observation of the resonance tunneling in field emission structures // J. Vac. Sci. Technol. $B, 17$ (2), pp. 655-658 (1999).

12. A.A. Evtukh, E.B. Kaganovich, V.G. Litovchenko, Yu.M. Litvin, D.V. Fedin, E.G. Manoilov, S.V. Svechnikov, Silicon tip arrays with nanocomposite film for electron field emission. // Mat. Sci. and Engin. C, 19, pp. 401-405 (2002).

13. G. Fursey, Early field emission studies of semiconductors // Appl. Surf. Sci., 94/95, pp. 44-59 (1996).

14. H. Hartnagel, Effects in the field emission for micro-size structures // Proc. 1st Ukrainian Sci. Conf. On Semicond. Phys., 10-14 Sept., 2002, Odessa, Ukraine. Abstracts, 1, pp. 47-48.

15. V.N. Tondare, B.I. Birajdar, N. Pradeep, D.S. Joag, A. Lobo, S.K. Kulkarni, Self-assembled Ge nanostructures as field emitters // Appl. Phys. Lett., 77 (15), pp. $2394-2396$ (2000).

16. A.A. Dadykin, Y.N. Kozyrev, Yu.M. Litvin, A.G. Naumovets, V.M. Ogenko, M.Yu. Rubezhanska, A.A. Chuiko, Quantumdimensional effects in field emission from Ge-Si nanocluster heterostructures // Proc. 15th Intern. Vac. Microel. Conf., 711 July, Lyon, France, OA. 3.08, pp. 300-302. 